\title{
ANALISIS DECISION SUPPORT SYSTEM UKM RUMPUT LAUT (USAHA RUMPUT LAUT BAPAK JAKA DI PANTAI AMAL)
}

\author{
ANALYSIS OF DICISION SUPPORT SYSTEM MICRO SMALL AND MEDIUM \\ ENTERPRISES SEAWEED \\ (SEAWEED BUSINESS, MR. JAKA ON THE BEACH AMAL)
}

Said Usman

(Universitas Borneo Tarakan)

\begin{abstract}
Abstrak: Penelitian ini bertujuan untuk mengetahui dan menganalisa bagaimana gambaran UKM rumput laut di pantai amal. Hasil penelitian ini adalah dinilai usaha ukm rumput laut milik Pak jaka digolongkan masih kurang layak untuk dijalankan dikarenakan dari aspekaspek yang dinilai hanya 2 aspek yang cukup atau melebihi setengah dari nilai skor yang diberikan. Kedua aspek tesebut meliputi Aspek Produksi dengan nilai 15 dari skor 28, dan yang kedua yaitu Aspek Lingkungan dengan nilai 12 dari 24.
\end{abstract}

\section{Kata Kunci : UKM}

Abstract: This study aims to find out and analyza how the picture of seaweed SMES on a Amal Beach. The results of this study were assessed that pak Jaka's SMEs business was classified as still not feasible to run because of the aspects that were assessed only 2 aspects werw sufficient or exceeded half of the scores given. Both aspects cover aspects of production with a value of 15 from a score of 28 and the second, an environmental aspect with a value of 12 out of 24 .

Keyword: Micro Small and Medium Enterprises

\section{LATAR BELAKANG}

Indonesia merupakan negara kepulauan yang memiliki potensi perikanan dan kelautan yang melimpah. Salah satu komoditi yang dikembangkan adalah rumput laut. Agribisnis rumput laut termasuk didalamnya industri pengolahan rumput laut menjadi berbagai macam makanan seperti dodol, kripik, dan lain-lain telah banyak dikembangkan oleh berbagai kalangan, khususnya kalangan menengah ke bawah. Hal ini dapat memicu peningkatan pertumbuhan ekonomi Indonesia.

Salah satu wilayah yang mengembangkan rumput laut baik secara budidaya atau pengolahan rumput laut adalah kota Tarakan. Potensi rumput laut di kota Tarakan cukup besar bahkan rumput laut menjadi trend di masyarakat khususnya wilayah kelurahan Pantai Amal. Banyak masyarakat yang berbondong-bondong mengembangkan rumput laut karena potensi rumput laut di masa depan cukup cerah.

Peningkatan produksi rumput laut pada tahun 2011 sebesar 1259.6 ton, kemudian pada tahun 2012 meningkat sebesar 273.48 ton (Badan Pusat Statistika Kota Tarakan, 2014). Peningkatan produksi rumput laut di kota Tarakan berbanding terbalik dengan harga rumput laut, sehingga pendapatan yang diperoleh oleh para petani rumput laut belum maksimal. Hal ini tidak sebanding dengan banyaknya tenaga yang dikeluarkan oleh para petani mulai dari pembudidayaan hingga pengeringan rumput laut. Oleh karena itu, pengolahan rumput laut menjadi berbagai makanan dan camilan perlu diterapkan.

Perkembangan unit usaha menurut jenis usaha pada tahun 2006-2012 mengalami peningkatan cukup banyak khususnya pada industri kecil. Pada tahun 2006, industri kecil di kota Tarakan 
berjumlah 328 unit usaha. Sedangkan pada tahun 2012, industri kecil di kota Tarakan berjumlah 453 unit usaha (BPS Kota Tarakan, 2014).

Pada industri menengah juga mengalami peningkatan sebesar 10 unit usaha, yaitu pada tahun 2006 sebanyak 21 unit usaha dan pada tahun 2012 sebanyak 31 unit usaha. Sedangkan pada industri besar, banyaknya unit usaha di kota Tarakan sebesar 14 unit usaha pada tahun 2006 dan 2012. Namun selama kurun waktu 6 tahun terus mengalami kondisi fluktuatif (BPS Kota Tarakan, 2014). Berdasarkan kondisi diatas dapat disimpulkan bahwa industri kecil menguasai pasar industri kota Tarakan dan peluang dalam mengembangan industri kecil cukup besar.

Beberapa fakta diatas dapat dipastikan bahwa industri kecil pengolahan rumput laut masih terbilang kecil. Hal ini dapat dibuktikan dengan adanya data Usaha Mikro Kecil dan Menengah (UMKM) pada pengolahan rumput laut di kota Tarakan hanya terdapat dua unit usaha yang terdaftar di Dinas Kelautan dan Perikanan (DKP). Oleh sebab itu, perlu adanya peningkatan dan pengembangan usaha khususnya industri kecil/rumah tangga pada pengolahan rumput laut.

Inovasi pada pengolahan rumput laut dapat meningkatkan nilai tambah rumput laut, sehingga petani dapat meningkatkan pendapatan. Berdasarkan latar belakang tersebut, maka kami tertarik untuk meneliti "Analisis Decision Support System UKM Rumput Laut".

\section{RUMUSAN MASALAH}

Adapun perumusan masalah dalam penelitian ini adalah: Bagaimanakah gambaran UKM rumput laut yang ada di pantai amal ?

\section{TUJUAN PENELITIAN}

Adapun tujuan penelitian ini adalah:

1. Tujuan operasional dari penelitian ini adalah untuk mengetahui dan menganalisa bagaimana gambaran UKM rumput laut di pantai amal

2. Tujuan Fungsional dari penelitian ini yaitu agar hasil dari penelitian yang telah dilakukan dapat dimanfaatkan dan digunakan oleh pembaca sebagai bahan referensi dasar.

3. Tujuan Individual adalah untuk menambah ilmu pengetahuan, pengalaman, pengenalan, pengamatan dan memenuhi tugas dari mata kuliah ekonomi pesisir dan kelautan.

\section{TINJAUAN PUSTAKA}

\section{Teori Rumput Laut}

Rumput laut tergolong tanaman tingkat rendah, tidak mempunyai akar, batang maupun daun sejati, tetapi hanya menyerupai batang yang disebut thallus, tumbuh di alam dengan melekatkan dirinya pada karang, lumpur, pasir, batu dan benda keras lainnya. Secara taksonomi dikelompokkan ke dalam divisio Thallophyta (Kasmar dan Jakfar).

Berdasarkan kandungan pigmennya, rumput laut dikelompokan ke dalam empat kelas (Kasmar dan Jakfar), yaitu:

Rhodophyceae (ganggang merah)

b. Phaeophyceae (ganggang coklat)

c. Chlorophyceae (ganggang hijau)

d. Cyanophyceae (ganggang biru)

Jenis rumput laut yang paling banyak dibudidayakan di Indonesia adalah kelas Rhodophyceae yang mengandung agar-agar dan karaginan. Alga yang termasuk ke dalam kelas Rhodophyceae yang mengandung karaginan adalah Eucheuma dengan nama lokal agar-agar. Eucheuma cottonii memiliki thalus dengan permukaan licin; cartilageneus (menyerupai tulang rawan/muda); berwarna hijau terang, hijau olive, dan cokelat kemerahan. Percabangan thallus berujung runcing atau tumpul, ditumbuhi nodulus (tonjolan-tonjolan), dan duri lunak/tumpul untuk melindungi gametangia.

Percabangan bersifat alternatus (berseling), tidak teratur, serta dapat bersifat dichotomus (percabangan dua-dua) atau trichotomus (sistem percabangan tiga-tiga) 
Rumput laut Eucheuma cottonii memerlukan sinar matahari untuk proses fotosintesis. Oleh karena itu, rumput laut jenis ini hanya mungkin hidup pada lapisan fotik, yaitu kedalaman sejauh sinar matahari masih mampu mencapainya. Di alam, jenis ini biasanya hidup berkumpul dalam satu komoditas atau koloni. Eucheuma cottonii tumbuh di rataan terumbu karang dangkal sampai kedalaman melekat di batu karang, cangkang kerang, dan benda keras lainnya. Faktor yang sangat berpengaruh pada pertumbuhan jenis ini adalah cukup arus dengan salinitas (kadar garam) yang stabil, yaitu berkisar $28-34$ per mil. Oleh karenanya, rumput laut jenis ini akan hidup baik bila jauh dari muara sungai. Jenis ini telah dibudidayakan dengan cara diikat pada tali sehingga tidak perlu melekat ada substrat karang atau benda lainnya.

\section{Teori Tentang Industri/Produksi}

a. Bintarto, 1987. Industri adalah bagian dari proses produksi dimana bagian dari proses produksi itu tidak mengambil bahan-bahan langsung dari alam yang kemudianm mengolahnya hingga menjadi barang yang bernilai bagi masyarakat.

b. I Made Sandi, 1985:148, Industri adalah usaha untuk memproduksi barang jadi dengan bahan baku atau bahan mentah melalui proses produksi penggarapan dalam jumlah besar sehingga barang tersebut dapat diperoleh dengan harga serendah mungkin tetapi dengan mutu setinggi-tingginya.

\section{$\underline{\text { Teori UKM }}$}

Menurut Rudjito (2003) Usaha Kecil dan Menengah (UKM) di Indonesia yang memiliki peranan yang penting dalam perekonomian Indonesia, baik ditinjau dari segi jumlah usaha maupun dari segi penciptaan lapangan kerja. Definisi UMKM yang diberikan oleh beberapa lembaga, yaitu:

Dalam Pasal 1 ayat 1 Undang-Undang Nomor 20 tahun 2008 tentang Usaha Mikro Kecil dan Menengah bahwa yang dimaksud
Usaha Mikro adalah : "Usaha Mikro adalah usaha produktif milik orang perorangan dan/atau badan usaha perorangan yang memenuhi Usaha Mikro, sebagaimana diatur dalam Undang- Undang ini”.

\section{Definisi Konsepsional}

1. Studi kelayakan adalah Menurut Sutrisno (1982;75) Studi Keyakan (Feasibility study) adalah suatu studi atau pengkajian apakah suatu usulan proyek/gagasan usaha apabila dilaksanakan dapat berjalan dan berkembang sesuai dengan tujuannya atau tidak. Objek atau subjeck maters studi kelayakan adalah usulan proyek/gagasan usaha. Usulan proyek/gagasan usaha tersebut dikaji, diteliti, dan diselidiki dari berbagai aspek tertentu apakah memenuhi persyaratan untuk dapat berkembang atau tidak. Dalam studi kelayakan yang distudi (diteliti) misalnya aspek pemasaran, aspek tehnik, aspek proses termasuk input, out put dan pemasaran, aspek komersial, aspek yuridis, aspek social budaya, aspek paedagogis dan aspek ekonomi.

2. Usaha rumput laut adalah Rumput laut merupakan salah satu sumber daya hayati yang terdapat di wilayah pesisir dan laut. Istilah "rumput laut" adalah rancu secara botani karena dipakai untuk 2 kelompok "tumbuhan" yang berbeda. Dalam bahasa Indonesia, istilah rumput laut dipakai untuk menyebut baik gulma laut dan lamun. Yang dimaksud sebagai gulma laut adalah anggota dari kelompok vegetasi yang dikenal sebagai alga (ganggang). Sumber daya ini biasanya dapat ditemui diperairan yang berasosiasi dengan keberadaan ekosistem trumbu karang. Gulma laut alam biasanya dapat dihidup di atas subtrat pasir dan karang mati. Selain hidup bebas di alam, beberapa jenis gulma laut juka banyak dibudidayakan oleh sebagian masyarakat pesisir Indonesia. 


\section{METODOLOGI PENELITIAN}

Lokasi dan Waktu Penelitian

Penelitian ini dilaksanakan di Kota Tarakan, Provinsi Kalimantan Utara tepatnya di Kelurahan Pantai Amal.

Metode Pengumpulan Data dan Analisis Data

Penelitian ini dilakukan secara langsung terhadap objeknya, denganmendatangi tempat usaha tersebut unuk mengetahui lokasi tempat usaha,kegiatan yang berjalan, dan mendapatkan data-data primer yang akurat.Wawancara dilakukan langsung dengan pemilik usaha untuk mendapatkandan melengkapi data sekunder, serta informasi yang akurat tentang ruanglingkup kegiatan usaha UKM rumput laut.

Dari data yang akan di dapatkan nanti kami akan mengelolah data dengan memakai aplikasi DSS (Decision Support System) yang bisa di buka di http://dss.smecda.com/ .System pendukung keputusan atau DSS digunakan untuk mengumpulkan data, menganalisa dan membentuk data yang dikoreksi, dan mengambil keputusan yang benar atau membangun strategi dari analisis, tidak pengaruh terhadap computer, basis data atau manusia penggunanya.

\section{HASIL PENELITIAN}

\section{$\underline{\text { Aspek Produksi }}$}

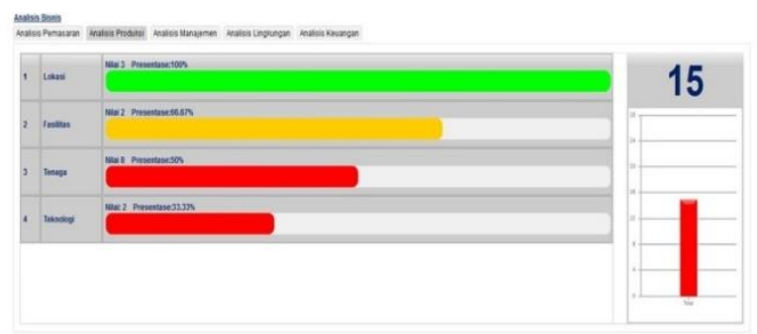

\section{Gambar 1. Aspek Produksi}

Dari aspek produksi dapat dilihat dari dari gambar 1 lokasi mendapatkan presentase $100 \%$ dalam artian tempat lokasi usaha mudah dijangkau. Dan dari segi fasilitas mendapatkan presentase $66.67 \%$ yang dalam artian fasilitas yang menunjang yang meliputi dari jumlah sarana peralatan yamg dimiliki perusahaan kami mendapatkan nilai cukup. Dari segi tenaga yang meliputi ketersediaan tenaga kerja, daerah asal, kebutuhan, dan upah tenaga kerja, kami mendapatkan nilai presentase $50 \%$ dalam artian dalam empat variabel yang kami gunakan kami mendapatkan nilai cukup. Sedangkan dari segi teknologi kami mendapatkan presentase $33.33 \%$ yang menggambarkan bahwa minimnya penggunaan teknologi sangat minim. Jika di jumlah dari keempat segi mendapatkan nilai 15 dari 28 skor, yang berarti mendapatkan nilai cukup dari segi aspek produksi.

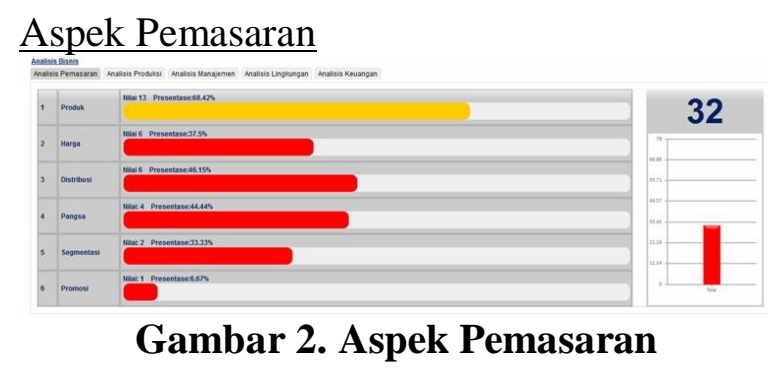

Dari aspek pemasaran yang bisa dilihat dari gambar 2 kami mendapatkan nilai presentase $68.42 \%$ dari segi produksi, yang menggambarkan bahwa dari segi produksi dapat di nilai sangat cukup yang meliputi kualitas barang, barang yang dijual, tingkat pemesanan, keragaman, dan spesifikasi barang. Dari segi harga kami mendapatkan nilai presentase sebesar $37.5 \%$ yang dapat dinilai rendah yang disebabkan oleh factorfaktor yang mempengaruhi harga barang banyak dan penetapan harga yang fluktuatif. Dari segi distribusi kami mendapatkan nilai presentase sebesar $46.15 \%$ yang dinilai masih rendah akibat dari wilayah penjualan yang masih dalam lingkup kabupaten dan kota. Dari segi pangsa kami mendapatkan nilai presentase sebesar $44.44 \%$ yang dinilai masih rendah yang disebabkan oleh rantai penjualan yang masih internal dan pasar yang mampu dikuasai sedang. Dari segi segmentasi mendapatkan nilai presentase sebesar $33.33 \%$ yang dinilai rendah yang 
disebabkan oleh tidak tersegmentasinnya pasar yang dibidik. Sedangkan dari segi promosi mendapatkan nilai presentase $6.67 \%$ yang dinilai sangat rendah yang disebabkan karena tidak adanya kegiatan promosi yang dilakukan. Dari keseluruhan segi yang dinilai kemudian di jumlahkan mendapatkan nilai 32 dari 78 yang bisa di simpulkan masih rendah.

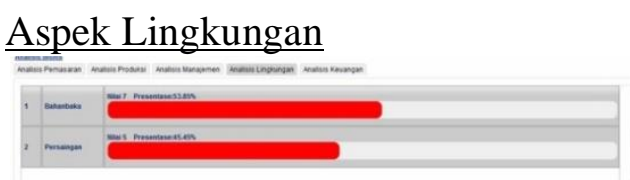

\section{Gambar 3. Aspek Lingkungan}

Dari gambar 3 yakni penilaian dari aspek lingkungan kami mendapatkan nilai presentase $53.85 \%$ dari segi bahan baku, yang dinilai dari persediaan barang yang masih langka. Dari segi persaingan mendapatkan nilai presentase sebesar $45.45 \%$ yang disebabkan oleh pesaing dalam usaha sejenis banyak dan jarak usaha sejenis yang kurang dari 1KM. Sehingga mendapatkan nilai 12 dari 24 yang dapat disimpulkan cukup.
Aspek Manajeman dan SDM

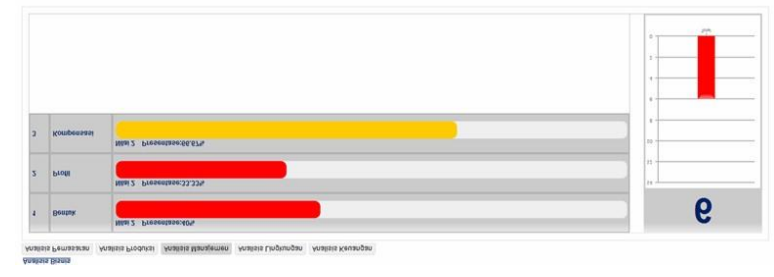

\section{Gambar 4. Aspek Manajemen dan SDM}

Dilihat dari gambar 4 dari aspek manajemen dan SDM yang meluputi segi bentuk mendapatkan nilai presentase $40 \%$ yang disebabkan oleh tidak adanya badan hukum dan izin perusahaan. Dari segi profil mendapatkan nilai $33.33 \%$ yang dinilai rendah diakibatkan oleh skala usaha yang mikro dan sistem pengolahaan yang masih sederhana. Sedangkan dari segi kompensasi mendapatkan nilai presentase $66.67 \%$ yang dinilai cukup karena nilainya sama dengan kompensasi yang diberikan oleh usaha sejenis. Dari tiga aspek yang dinilai di jumlahkan sehingga mendapatkan nilai sebesar 6 dari 14 yang dapat digolongkan masih rendah.

\section{KESIMPULAN}

Dari data yang didaptkan dan dinilai usaha ukm rumput laut milik Pak jaka digolongkan masih kurang layak untuk dijalankan dikarenakan dari aspek-aspek yang dinilai hanya 2 aspek yang cukup atau melebihi setengah dari nilai skor yang diberikan. Dan dapat juga disimpulkan bahwa ketidaktauan Pak Jaka mengenai keadaan pasar bisa memperburuk keadaan usaha yang dijalankan dalam kedepannya, serta masih kurangnya penggunaan teknologi yang dapat menunjang usaha

\section{DAFTAR PUSTAKA} Kota Tarakan.

Rudjito.2003. Strategi Pengembangan

UMKM Berbasis Sinergi Bisnis, Makalah Yang Disampaikan Pada Seminar Peran Perbankan Dalam 
Memperkokoh Ketahanan Nasional Kerjasama Lemhanas RI dengan BRI, April.

Sutrisno.1982. Pengantar Studi Kelayakan Suatu Proyek. Yogyakarta: BPFE.

Kasmir dan Jakfar. Studi Kelayakan Bisnis , Kencana prenada media group, Jakarta, cep. 9 April, 2013 